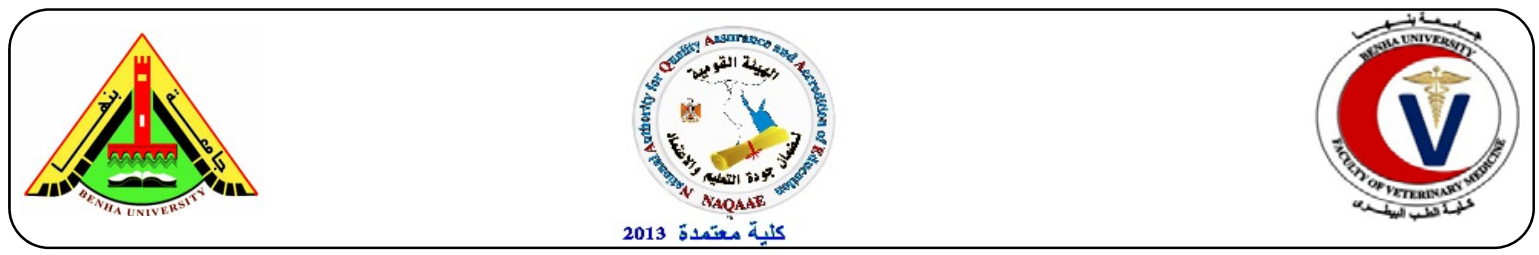

\title{
Surgical management of pectoral limb long bone fractures in dogs: Clinical and Radiographical studies.
}

\author{
Abou-El-Fetouh., M.M' ${ }^{1}$; Al-Akraa., A.M ${ }^{1}$ and Gadallah., S.M ${ }^{2}$ \\ ${ }^{1}$ Department of surgery, Faculty of Veterinary Medicine, Benha University, Egypt. ${ }^{2}$ Department of \\ surgery, Faculty of Veterinary Medicine, Saddat University, Egypt. \\ Email: mahmoud.abouelfetouh@fvtm.bu.edu.eg
}

\section{A B S T R A C T}

This study was carried out on 27 adult male mongrel dogs. These dogs were subjected to an artificial induction of diaphyseal fractures including the long bones of the pectoral limb (humerus, radius \& ulna and metacarpal). The induced fractures were managed surgically via different fixation techniques (bone plating, intramedullary bone pinning (IMP) and unilateral transkeletal fixation (TSF) as well as application of plaster of Paris bandages). The obtained results were evaluated clinically and radiographically. The present study aimed to record the clinical signs and radiographic improvement and post-operative complications of such techniques and additional aim was to suggest the best method for fixation of diaphyseal fractures of long bone of pectoral limb.

Key words: Pectoral limb, fractures, fixation methods, healing evaluation.

(BVMJ-29(1): 17-25, 2015)

\section{INTRODUCTION}

$\mathrm{F}$ orelimb fractures is particularly challenging in orthopaedic surgery as dogs bear most of their weight with the thoracic limbs (Simpson, 2004 and Simon et al., 2011). The incidence of thoracic limb fractures is highest in young animals below the age of six months. Male dogs are affected more than female dogs of all age (Wong, 1984; Cook et al., 1997; Dvorak et al., 2000; Shiju et al., 2010 and Simon et al., 2011). Most fractures of the humerus occurred in the middle and distal third. (Unger et al., 1990 and Jackson, 1998 and Piermattei et al., 2006). The diaphyseal fractures of radius and ulna are common especially the middle and the distal third of the diaphysis (Sardinas and Montavon, 1997 and Milovancev and Ralphs, 2004). High incidence of the metacarpal fractures occurred in the main weight bearing bones $\left(3^{\text {rd }}\right.$ and $4^{\text {th }}$ metacarpal fractures) (Degasperi et al., 2007). Pectoral limb fractures are due to high energy trauma and therefore can result in both life threatening injuries and severe and permanent disability (Fossum et al., 2013). Understanding the different types of fracture and their incidence will be helpful to develop improved techniques of fracture fixation in dogs (Piermattei et al., 2006). The perfect bone healing requires accurate reduction of fracture fragments and rigid fixation (Turner, 2005 and Fossum, 2013). The aim of the present study is to evaluate clinically and radiographically the efficacy of different fixation techniques in repair of an experimentally induced long bones pectoral limb fractures in dogs.

\section{MATERIAL AND METHODS}

\subsection{Animals}

This study was performed on twenty seven mongrel male dogs of an average weight (17 $\pm 6 \mathrm{~kg} \mathrm{b.wt})$ and average age (12 \pm 6 months). These dogs were clinically 
apparent healthy. These dogs were divided into three groups as shown in Table (1). Group (1): (Humeral diaphyseal fractures): Experimentally induced traumatic fractures of humeral shaft were made in nine dogs. These fractures were fixed by different fixation methods using bone plating techniques (3dogs), IMP (3dogs) and unilateral Acrylic TSF (3dogs). Group (2) (Radial and ulnar diaphyseal fractures): Experimentally induced traumatic fractures of radial and ulnar shaft were made in nine dogs. These fractures were stabilized by different methods of fixations as bone plating technique (3dogs), unilateral Acrylic TSF (3dogs) and gypsona bandages (3 dogs). Group (3) (Metacarpal diaphyseal fractures): Experimentally induced traumatic fractures of metacarpal shafts were made in nine dogs. These fractures were fixed by different methods as bone plating technique (3dogs), IMP (3 dogs) and gypsona bandages (3dogs).

Table (1): The number of the animals and methods of fixation in each group.

\begin{tabular}{|c|c|c|c|c|c|}
\hline \multirow[b]{2}{*}{ Gro } & \multirow{2}{*}{$\begin{array}{l}\text { Type of the } \\
\text { long bone. }\end{array}$} & \multicolumn{2}{|c|}{ External fixation } & \multicolumn{2}{|c|}{ Internal fixatio } \\
\hline & & $\begin{array}{c}\text { External } \\
\text { Co-aptatior } \\
\text { (gypsona) }\end{array}$ & $\begin{array}{l}\text { Externa } \\
\text { Skeleta } \\
\text { Fixatior }\end{array}$ & $\begin{array}{l}\text { Bone } \\
\text { Platinई }\end{array}$ & $\begin{array}{l}\text { Bor } \\
\text { Pinn }\end{array}$ \\
\hline
\end{tabular}

\begin{tabular}{lcccccc}
\hline Group1 & Humerus & 9 & - & 3 & 3 & 3 \\
Group2 & Radius and ulna & 9 & 3 & 3 & 3 & - \\
Group3 & Metacarpal & 9 & 3 & - & 3 & 3
\end{tabular}

\subsection{Anaethesia and control}

The operated selected region of pectoral limb should be prepared for aseptic condition. The dogs were premedicated with atropine sulphate S.C (atropine sulphate 1\% Adwia, Egypt. Co) in the dose $0.04 \mathrm{mg} / \mathrm{kg}$ body weight. General anaesthesia was induced using xylazine $\mathrm{Hcl}$ $2 \% \quad$ (Xylaject ${ }^{\circledR} \quad 2 \%$ Adwia, Egyptian Company) in dose of $1 \mathrm{mg} / \mathrm{kg}$ body weight \& ketamine Hcl (Ketamine $\AA$, Sigma, Egypt. Co) in dose of $10 \mathrm{mg} / \mathrm{kg}$ body weight together in the same syringe slowly IV. (Hall et al., 2001). The aneasthetic stage was maintained during surgery by using thiopental sodium 2.5\% (Epico, Egyptian company) in dose rate of $30 \mathrm{mg} / \mathrm{kg}$ body weight intravenously. Preoperative cefotaxime (Cefotax ${ }^{\circledR}$ Epico, Egypt. Co.) was administered in dose rate of $30 \mathrm{mg} / \mathrm{kg}$ body weight IM.

\subsection{Surgical management of humeral diaphyseal fractures}

The approach to the shaft of humerus was adopted after (Johnson, 2014). In which the shaft of humerus was exposed through the craniolateral aspect.

\subsubsection{Bone plating technique (Hickman and Walker, 1980).}

The induced fracture of shaft of humerus was fixed by $4.5 \mathrm{~mm}$ compression plating technique.

\subsubsection{Intramedullary pinning (Ayyappan et al., 2011).}

$(I M P)$

The intramedullary pin was introduced in retrograde fashion at the site of fracture in which the pin is driven proximally until it exits the proximal cortex at greater tubercle then driven distally to anchor it in medial aspect of distal humeral condyle.

\subsubsection{Acrylic unilateral TSF (poly methylmethacrylate, PMMA) (Fossum et al., 2013).}

A four positive end threaded transfixion pins $(3 \mathrm{~mm})$ were used. The fixation pins were fixed together with acrylic rod. (Acrostone ${ }^{\circledR}$ Acro. Dental. Egypt. Co.) 


\subsection{Management of radial and ulnar diaphyseal fractures:}

The mid shaft of radius was exposed after (Milovancev and Ralphs, 2004). The mid shaft of radius was exposed through lateral approach.

\subsubsection{Bone plating technique (Fossum et al., 2013).}

Dynamic compression (DC) $3.5 \mathrm{~mm} 8$ holes plate was used.

\subsubsection{Acrylic unilateral TSF (Piermattei et al., 2006).}

Four peripherally threaded Steinmann pins of $4 \mathrm{~mm}$ were used.

\subsubsection{External co-aptation by using plaster of paris bandages.}

The radial and ulnar fractures were casted by using $7.5-10 \mathrm{~cm}$ plaster of paris rolls (gypsona).

\subsection{Management of metacarpal diaphyseal fractures:-}

The shaft of metacarpal bones was exposed through a dorsal skin approach after (Degasperi et al, 2007).

\subsubsection{Bone plating (Kornmayer et al, 2013).}

The fractured metacarpal shafts $\left(3^{\text {rd }}\right.$ and $4^{\text {th }}$ ) were fixed by $2 \mathrm{~mm} 4$ holes mini plates.

\subsubsection{Intramedullary pinning}

(Werham and Roush, 2010).

(IMP)

The metacarpal shaft fractures $\left(3^{\text {rd }}\right.$ and $\left.4^{\text {th }}\right)$ were stabilized by using $1.5 \mathrm{~mm}$ kirshner wires.

\subsubsection{External co-aptation by using plaster of paris bandages.}

The metacarpal shaft fractures $\left(3^{\text {rd }}\right.$ and $\left.4^{\text {th }}\right)$ were stabilized externally by using 2 rolls of gypsona.

\subsection{Post-operative care}

Post-operative cefotaxime (Cefotax ${ }^{\circledR}$ Epico, Egyptian Company) was administered as dose rate of $30 \mathrm{mg} / \mathrm{kg}$ body weight intramuscular daily for 5 days. Nonsteroidal anti-inflammatory as Mobic
(Meloxicam) was also given in a dose of $0.2 \mathrm{mg} / \mathrm{kg}$ body weight. The dog's activities were limited. The wound incision was dressed and bandaged and inspected twice daily.

\subsection{Follow up examinations}

All dogs were observed and routinely evaluated clinically at walk and trot post operatively. The lameness was graded (lameness scoring) and radiographically. Radiographic examination was done immediately after operation and subsequent $\mathrm{X}$ rays checkups of 2 weeks intervals until the radiographic signs of fracture union were evident. The exposure factors of radiographic images was $50-60 \mathrm{KVp}$ and 6$10 \mathrm{mAs}$ with $80 \mathrm{~cm}$ FFD depending on the animal size and area to be viewed. Two perpendicular views (two orthogonal views) were taken by mobile simply HP X-ray machine.

\section{RESULTS}

\subsection{Clinical evaluation of reconstructed pectoral limb fractures}

In all dogs, One day after operation, the surgical wound showed the signs of inflammation as edematous swelling. The surgical wounds were healed completely after 7-10 days. In bone plating of humeral, metacarpal and radial shaft fractures, six to eight weeks post operatively; the dogs walk normally with full functional use of limb with no lameness and slight signs of lameness when running Fig (1A) and Fig (4A). In IMP of humeral and metacarpals shaft fractures, one day after operation, the operated limb just touch the ground with no weight bearing Fig (2A). Within three months, there is progressive improvement in limb use with complete weight bearing with no lameness Fig (2B). In unilateral acrylic TSF of radial fractures, pin tract discharges were observed in most dogs. After three to four weeks, the dogs stand normally with some limb function with slight lameness when walk (Fig 3A). The dogs showed full limb use and walk and trot 
and run normally within two to three months. In bone plating of humeral fractures, one dog showed poor clinical signs after two weeks with obvious and continual lameness. This dog revealed clinical signs of severe wound infection. Two dogs showed continuous non weight bearing after 5 days of plating of humeral and radial fractures. These dogs showed radiographically failure of implant and loosening of screws Fig (7A \& B). Good clinical signs were obtained after removal of failed plate from the radius and treat the case external skeletal fixation. In IMP of humeral fractures, one dog showed no improvement in limb function with persistent partial weight bearing lameness. This dog revealed clinically draining tracts of exudates and radiographically signs of infection (Fig 7C). In external co-aptation with gypsona, Failure of gypsona was occurred in large weight breed but success in small weight breed. Some gypsona was damaged so it is needed for change. Pressure sores and swelling of the skin of digits were the common complications at these treated cases.

\subsection{Radiographic evaluation}

In most dogs, the post-operative radiographs showed good reduction and alignment of fracture fragments. In bone plating of humerus and metacarpals shaft fractures, the fracture healed with absence or little bridging callus around the fracture and the fracture line (Fig B). In bone plating of radial and ulnar shaft fractures: There was extensive callus around the ulnar fracture. Synostosis (Periosteal adhesion) was noted between the radius and ulna after repair of radial and ulnar fractures (Fig 4B). Extensive periosteal reaction was also noted around the plate. In IMP of humeral and metacarpals shaft fractures, Radiographic follow ups revealed secondary progressive callus formations mainly periosteal callus extending proximally and distally to the fracture Fig (2C and 6B). In unilateral acrylic TSF of radial fractures, callus formation around the fracture site with normal periosteal reaction around the pin insertion sites (Fig 3B). The increased bone density was also noted around the pin insertion sites. In external co-aptation of metacarpals fractures with plaster of paris bandages (Gypsona), fracture fragments of $3^{\text {rd }}$ metacarpal bone were healed with malposition (Fig 5B).
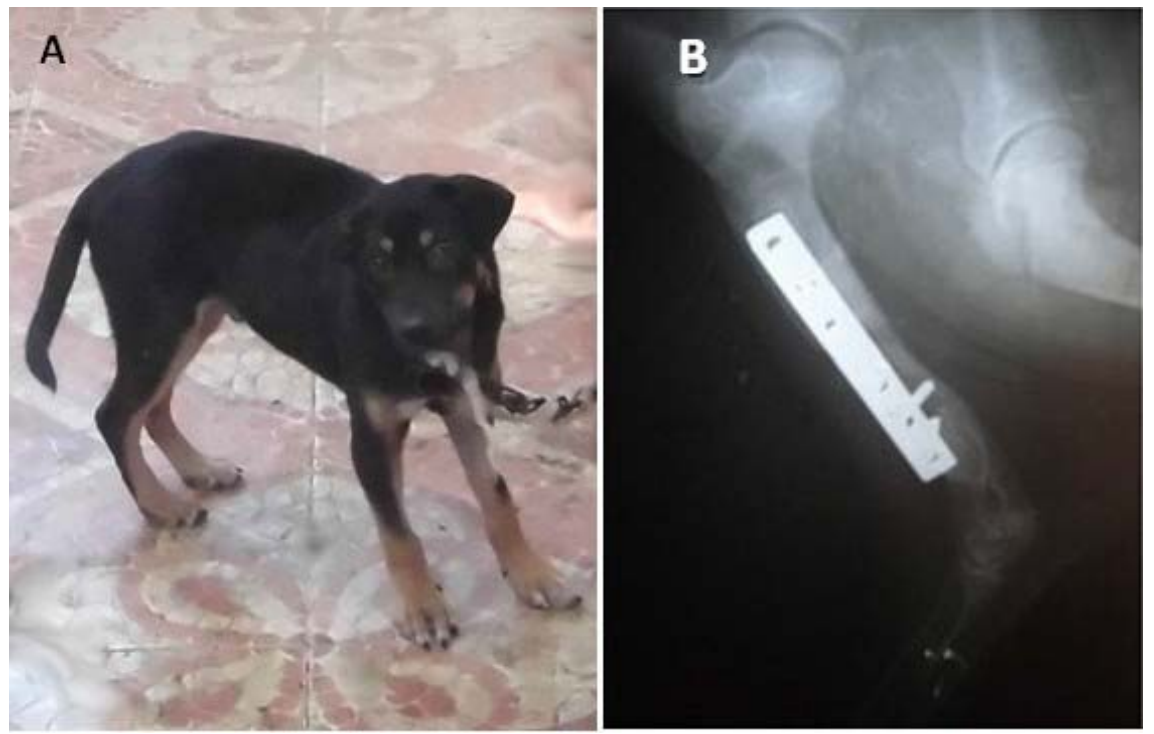

Fig (1): Showing full limb weight bearing in a dog with bone plating of humeral shaft fracture of right limb 2 months postoperatively (A). Mediolateral radiographic view 2 months postoperatively showing healing of transverse humeral fracture with intercortical callus with absence of bridging callus (B). 

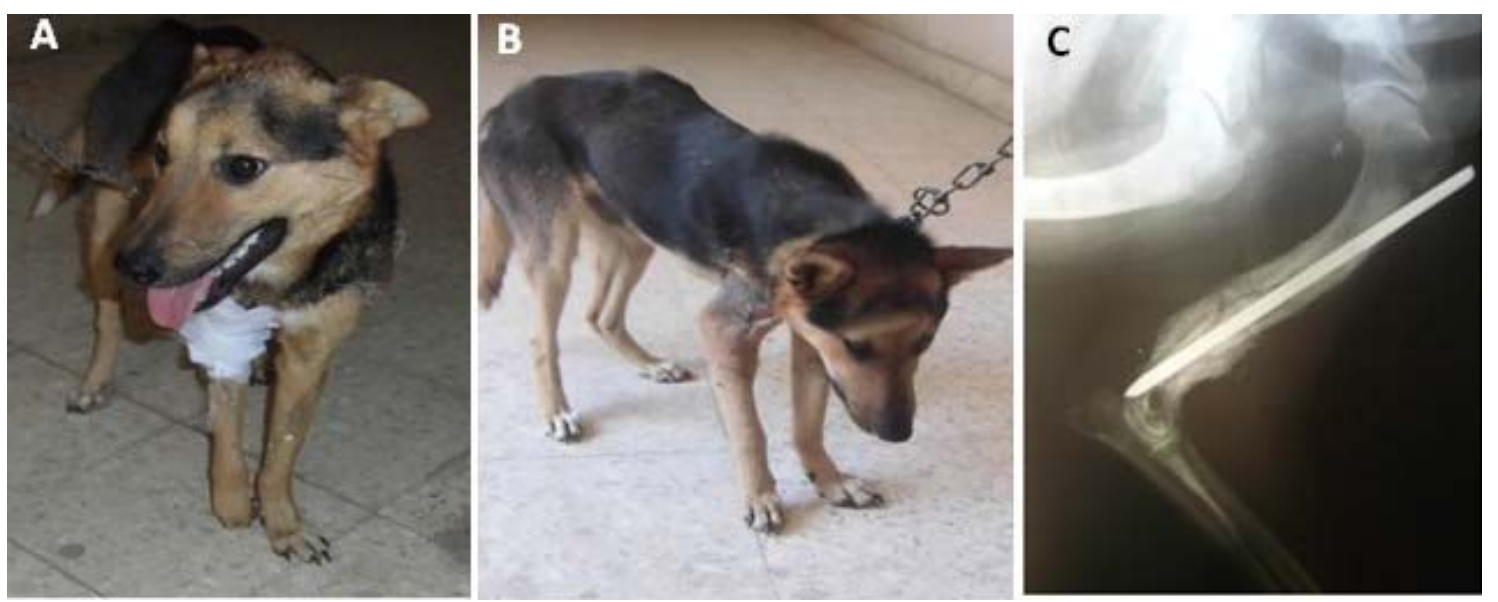

Fig (2): A dog with intramedullay pinning of humeral shaft fracture of right limb one day postoperatively, noticed that the operated limb just touch the ground with no weight bearing (A). A complete weight bearing of the same dog 3 months postoperatively (B). Lateromedial radiographic image 2 months postoperatively after intramedullary pinning of humeral shaft fracture showing the bridging callus around the fracture site $(\mathrm{C})$. Note that the fracture line nearly disappeared.

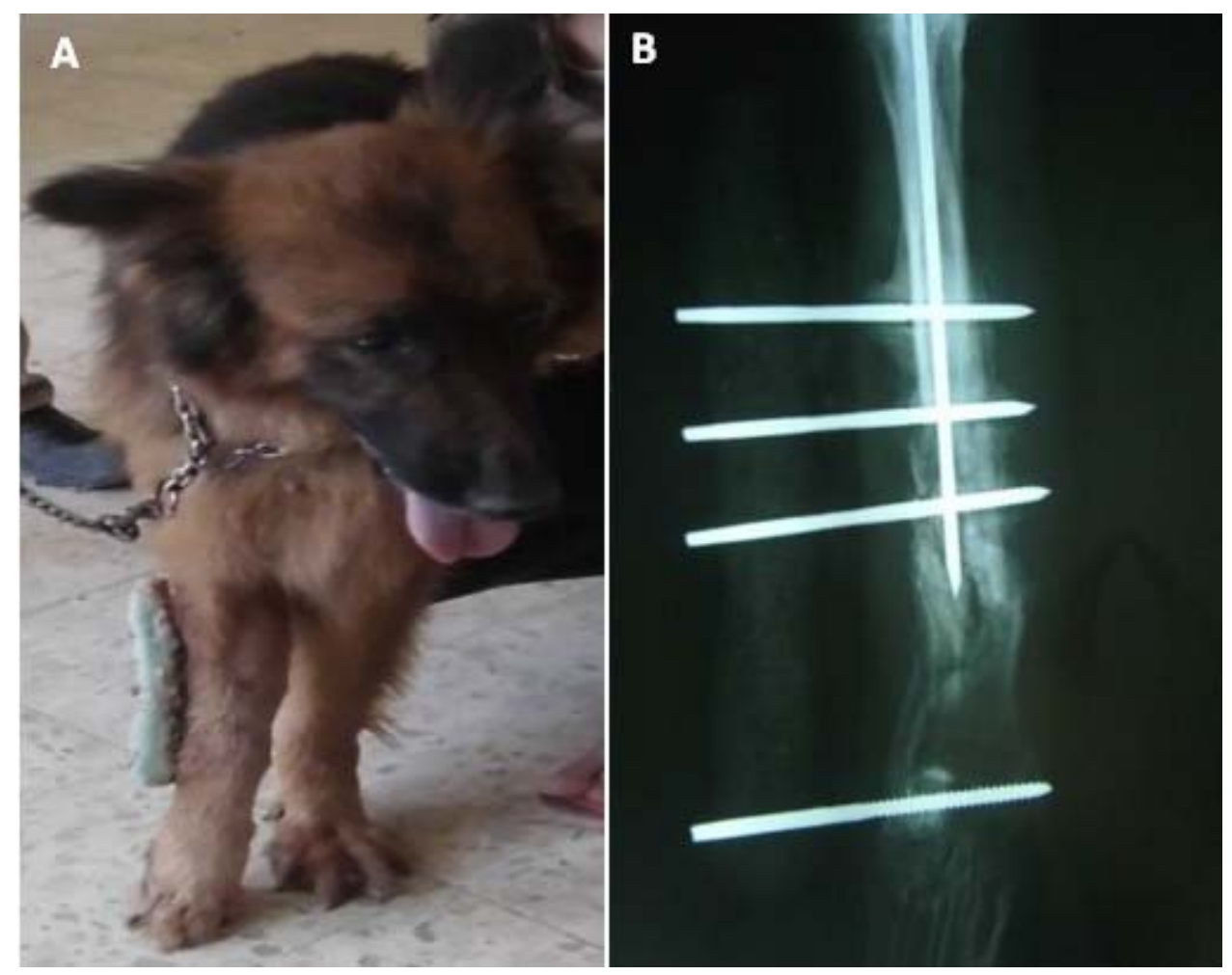

Fig (3): A partial weight bearing 1 month postoperatively after unilateral acrylic external fixation of radial shaft fracture of right limb (A). Craniocaudal radiographic view 2.5 months postoperatively after unilateral acrylic external fixation of radial shaft fracture showing increasing density of callus formation around the fracture and periosteal reaction around the fixation pins (B). 

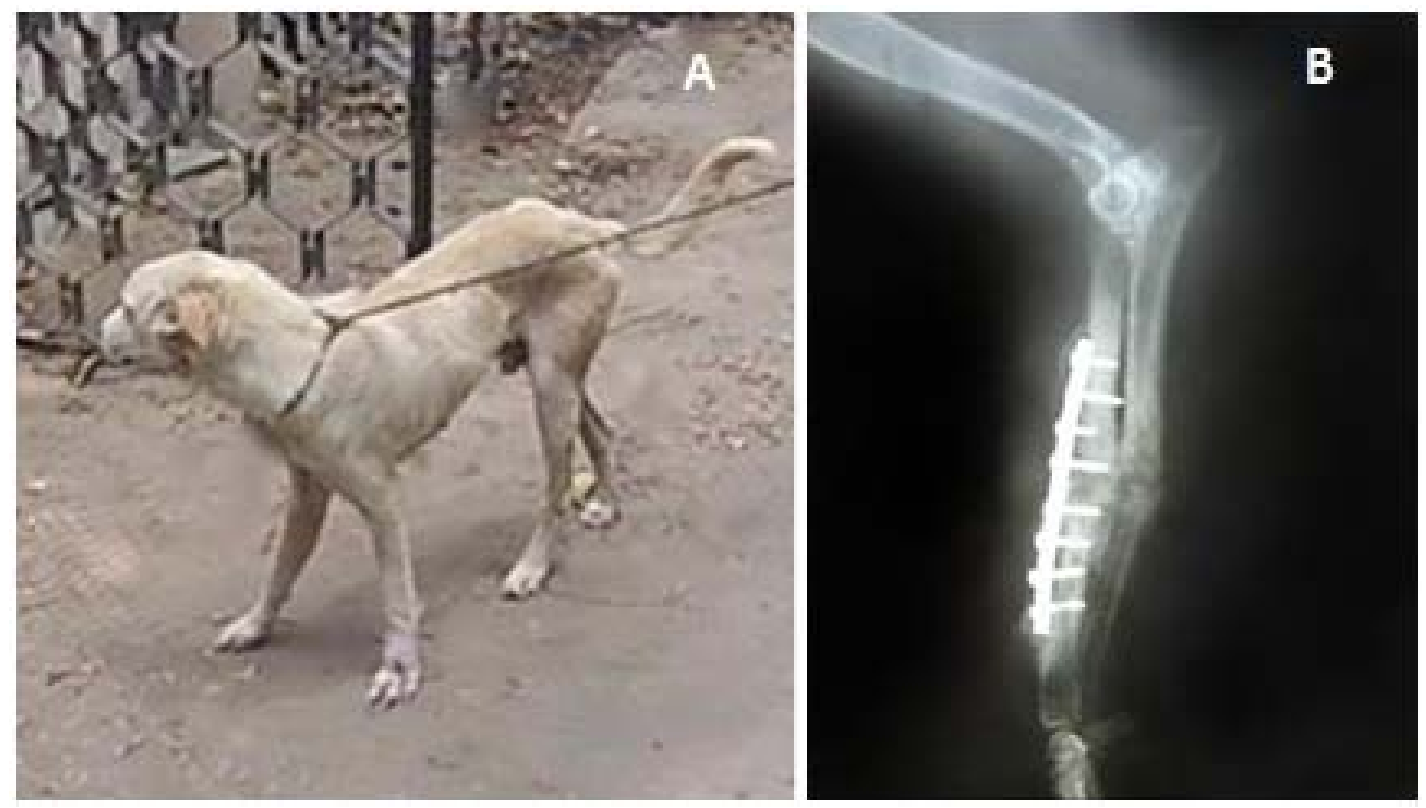

Fig(4): A complete weight bearing with full limb function after bone plating fixation of radial and ulnar shaft fracture of right limb 2 months postoperatively(A). Mediolateral radiographic inspection 3.5 months postoperatively after bone plating of radial and ulnar shaft fracture showing radial healing with little callus and ulnar healing with exuberant callus. Synostosis was also observed (B).

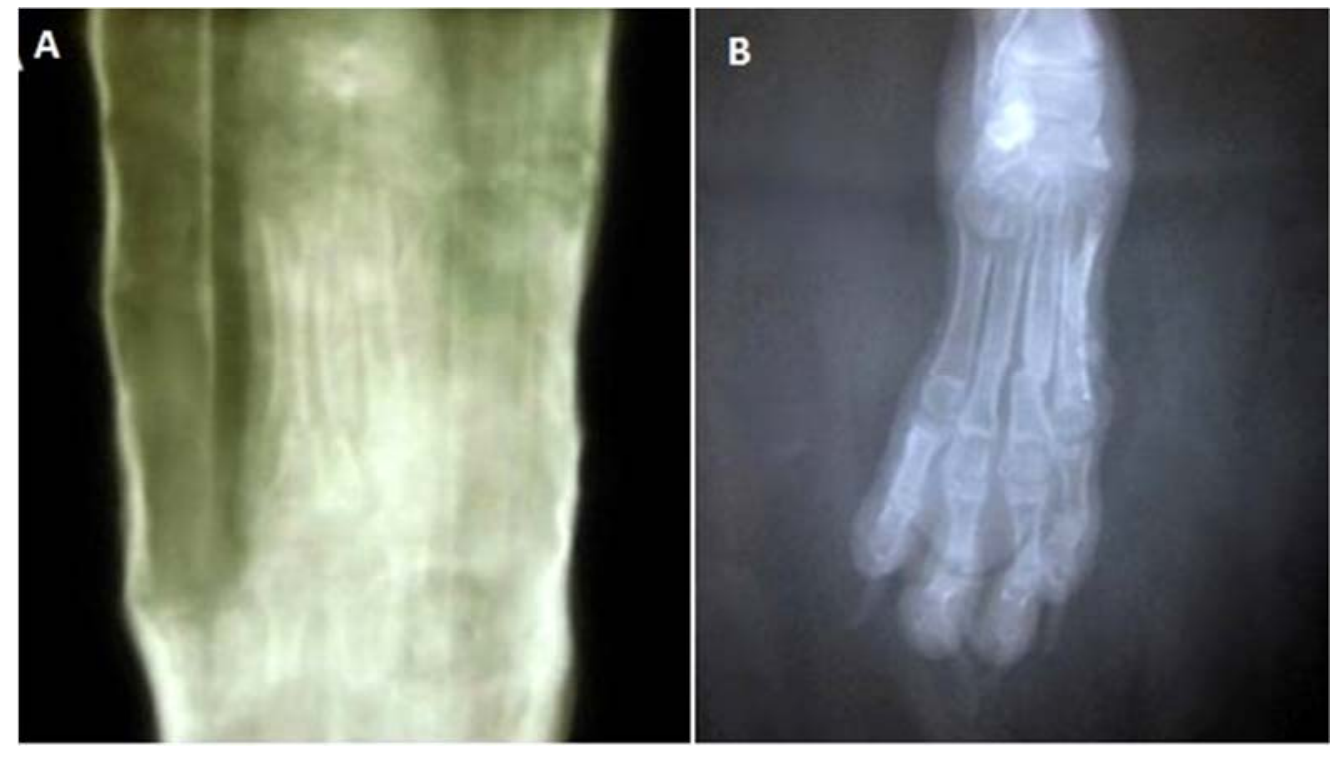

Fig(5): Dorso-palmer radiographic image 1 month postoperatively after external co-aptation of metacarpal shaft fractures showing malpposition of fracture fragments of metacarpals $\left(3^{\text {rd }}\right.$ and $4^{\text {th }}$ ) but the fracture healing begun at the contact parts of fracture fragments (A). Dorso-palmer radiographic view 2months postoperatively after removal of gypsona showing healing of metacarpal fractures but the $3^{\text {rd }}$ metacarpal fracture fragments were malpposed (B). 

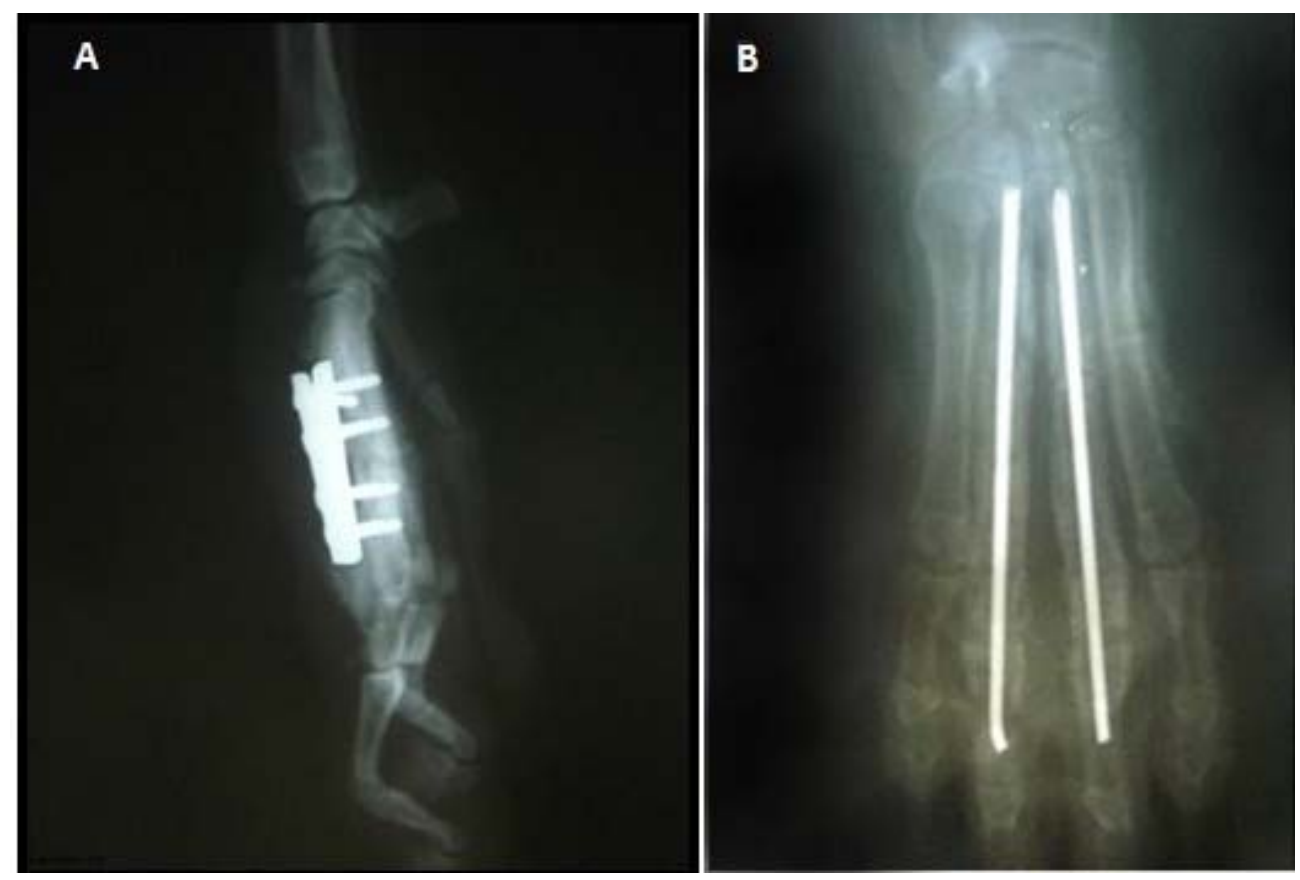

Fig(6): Mediolateral radiographic examination 45 days postoperatively after bone plating of metacarpal shaft fractures showing callus formation with nearly disappearance of fracture line (A). Dorso-palmer radiographic view 2.5 months postoperatively after intramedullary pinning of metacarpal shaft fractures showing callus formation and disappearance of fracture lines of fractured metacarpals $\left(3^{\text {rd }}\right.$ and $\left.4^{\text {th }}\right)(B)$.
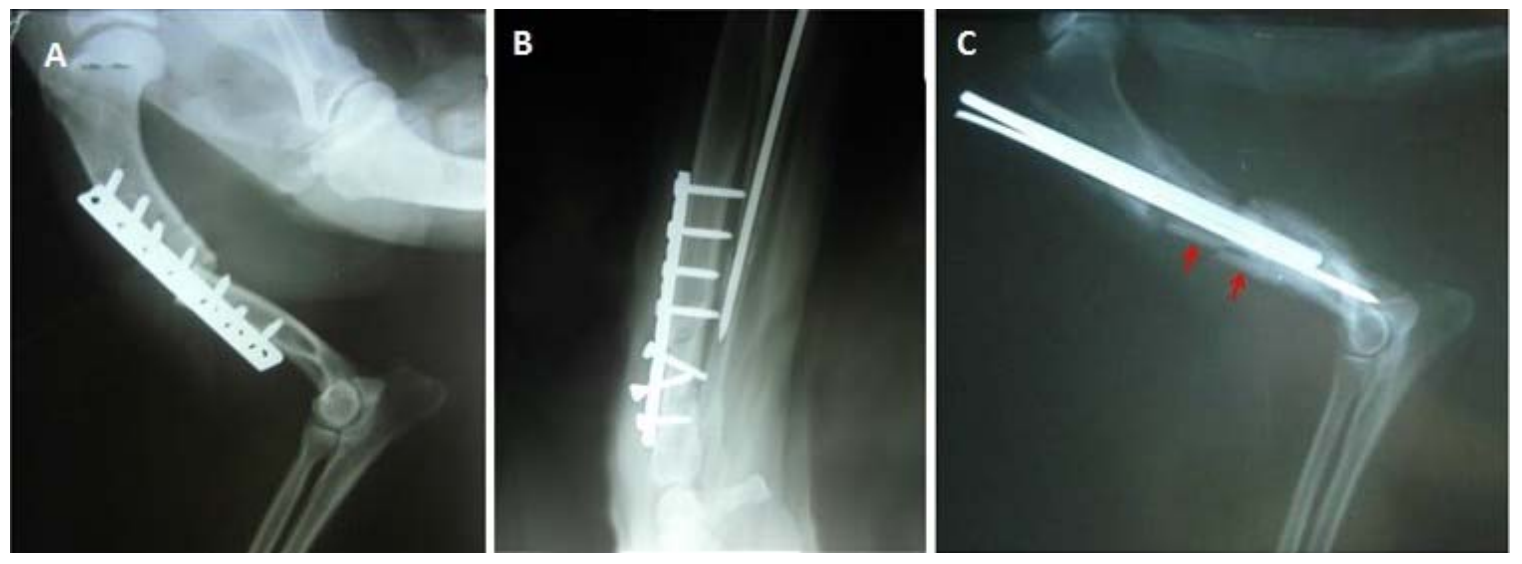

Fig(7): Mediolateral radiographic view of transverse humeral fracture plating 5 days postoperative showing failure of plate with bending and broken screws (A). Mediolateral radiographic image one week postoperatively after bone plating of radial shaft fracture showing implant failure and loosening of the three distal cortical screws (B). Mediolateral radiographic view one month post operatively after stack intramedullary pinning of transverse humeral fracture showing Osteomyelitis and lack of bone healing due to infection and a sequestrum including irregular periosteal reaction extended proximal and distal to the fracture site and areas of irregular bony reabsorption and destruction (arrows) (C). 


\section{DISCUSSION}

The craniolateral approach to the shaft of the humerus provides adequate exposure with minimal trauma to the soft and vascular tissues. This pronouncement is similar with that observed by Bardet et al., (1983) and Ayyappan et al., (2011). In the present study, minimal callus with disappearance of the fracture line was observed in radial fracture but there was extensive callus around the ulnar fracture. These was due to the radial fracture was well fixed and stabilized by bone plate but the ulna not fixed. This finding agrees with that reported by Burk and Feeney (2003). The posttraumatic synostosis between the radius and the ulna might occur after surgical treatment of radial and ulnar fractures. Dogs with a high activity level, comminuted fractures, and open fractures appear to be more likely subject of this complication. This was also reported by Langley-Hobbs et al., (1996). The radial repair provided a splint for ulnar fracture through its ligamentous attachment to radius but intramedullary pinning of ulna was made to stabilize the multiple ulnar fractures and provide additional support to the primary fixation of radial fracture. These were also reported by Hurov and Seer (1968), Olmstead and Newton (1990), Milovancev and Ralphs (2004) and Fossum et al., (2013). Plate failure in bone plating of humeral and radial fracture might caused by inability to implant to counteract the disruptive forces at the fracture site. This is agreed with that reported by Egger (1998);Olmstead (1991) and Piermattei et al., (2006). Maintenance of apposition of metacarpal fractures was lost when treated with gypsona. This due to it could not counteract the shear forces acting on the fracture site. This was also mentioned by Okumura et al., (2000) and Fossum et al., (2013).

The IMP of humeral shaft fracture is the most safe and cost-effective method and gives fewer complications. This result was also reported by Kumar and Gahlot (2013) and Asma et al., (2014). IMP of the humeral shaft fracture was performed through a limited open surgical approach than plating of the diaphyseal shaft fracture that was needed to exposure the whole humerus. Limited approach has less soft tissue damage and vascular damage enhancing in turn healing. This was also reported by Simpson (2004); Piermattei et al., (2006). and Von Pfeil et al., (2008). Unilateral acrylic TSF was better for diaphyseal fractures of the radius. This is agreed with that reported by Rochat (2001). Central weight bearing bones $\left(3^{\text {rd }}\right.$ and $4^{\text {th }}$ metacarpal bones) are best treated with open reduction and internal fixation. In this study, bone plating gave better result with few complications. This result is agreed with that reported by Bellenger et al., (1981); Okumura et al., (2000) and Kornmayer et al., (2014). The present study recommended that, the use of IMP for humeral shaft fractures because it gave very promising results with minimal complications in terms of rapid return to full limb function, rigid stability at the fracture site and cortical union. Unilateral TSF is the best method for radial shaft fractures. Bone plating gave also good results in treatment of radial and metacarpal shaft fractures $\left(3^{\text {rd }}\right.$ and $4^{\text {th }}$ metacarpal bones).

\section{REFERENCES}

Ayyappan, S, Simon, M.S., Das, B.c., Prasad, A.A., Kumar, R.S. 2011. Management of diaphyseal humeral fracture using plate rod technique in a dog. Tamilandu J.Vet and Anim. Sci. 7(1):35-38.

Bardet, J.F., Hohn, R.B., Rudy, R.L., Olmstead, M.L. 1983. Fractures of the humerus in dogs and cats. A retrospective study of 130 cases. Vet. Surg. 12:73-77.

Burk, R.L., Feeney, D.A. 2003. Small animal radiology and ultrasonography. The appendicular skeleton. Elsevier Science .St. Louis, Missouri. pp:477-300. 
Cook, J.L, Tomlinson, J.L, Millis, D.L, Starost, M., Albrecht, M.A., Payne, J.T. 1997. Scapular fractures in dogs: epidemiology, classification and concurrent injuries in105 cases (1988-1994). J. Am. Anim. Hosp. Associ. 33(6):528-532.

Degasperi, B., Gradner., G., Dupre, G. 2007. Intramedullary pinning of metacarpal and metatarsal fractures using a simple distraction technique. Vet. Surg. 36(4):382-388.

Dvorak, M., Necas, A., Zatloukal, J. 2000. Complications of long bone fracture healing in dogs: Functional and radiographical criteria for their assessment. Acta. Vet. Brono. 69: 107-114.

Egger, E.L. 1998. External skeletal fixation. In: Bojrab M.J. (ed.): Current Techniques in Small Animal Surgery. $\left(4^{\text {th }}\right.$ ed). William and wikins. Philadelphia. pp. 941-950.

Fossum, T.W., Johnson, A.L., Schulz, K.S., Willard, M.D., Horn, C.V., Dewy, C.W., Radlinsky, M.G., Macphail, C.M. 2013. Management of specific fractures. In Fossum et al, (eds). Small animal surgery ( $4^{\text {th }}$ ed). Elsevier, Mosby, St. Louis, Missouri. PP: 1030.

Hall, W.L., Clarke, W.K., Trim, M.C. 2001. Anaesthesia of the dog. In Hall et al (eds): Veterinary anaethesia $\left(10^{\text {th }}\right.$ ed). W.B. Saunders. pp. 1020-1030.

Hickman, J., Walker, R.G. 1980. An atlas of veterinary surgery. (Portuguese edition). John rights \& Sons. Ltd. pp. 235-237.

Johnson, K.A. 2014. Forelimb. In Johnson, K.A (ed). Piermattie's Atlas of surgical approaches to the bone and joints of the dogs and cat (5th ed).
Elsevier, Saunders, St. Louis, Missouri. pp. 160.

Kornmayer, M., Failing, K., Matis, U. 2014. Long-term prognosis of metacarpal and metatarsal fractures in dogs. Vet. Comp. Orthop. Traumatol. 20(4):256263.

Milovancev, M., Ralphs, S.C. 2004. Radius / ulna fracture repair. Clin. Tech. Small. Anim. Pract. 19(3):128133.

Piermattei, D.L., Flo, G.L., Decamp, C.E. 2006. Fractures and orthopaedic conditions of the forelimb. In Piermattei et al, (eds): Handbook of small animal orthopaedics and fracture repair $\left(4^{\text {th }}\right.$ ed $)$. Saunders. St. Louis, Missouri. pp. 255.

Rochat, M.C. 2001. Using external skeletal fixation to repair long bone fracture. Vet. Med., pp. 393-399.

Shiju, M.S., Ganesh, R., Ayyappan, S., Rao, G.D., Kumar, R.S., V.R. Kundave, V.R., Das, B.C. 2010. Incidence of pelvic limb fractures in dogs: a survey of 478 cases. Vet. World Journal 3(3):120-121.

Simon, M.S., Ganesh, R., Ayyappan, S., Kumar, R.S. 2011. Incidence of pectoral limb fractures in dogs: a survey of 331 cases. Tamilandu. J. Vet. Anim. Sci. 7: 94-96.

Simpson, A.M. 2004. Fractures of humerus. Clin. Tech. Small Anim. Pract. 19(3):120-127.

Werham, B.G.J. Roush, J.K. 2010. Metacarpal and metatarsal fractures in dogs. Compendium (Yardley, PA). 32(3). E1-7

Wong, W. T. 1984. A survey of fractures in the dog and cat in Malaysia. Vet. Record, 115(11):273-274. 